\title{
CONSTRUINDO A REDE TRANSNACIONAL UCHINAANCHU: UMA ETNOGRAFIA MULTISITUADA
}

\author{
Yoko Nitahara Souza ${ }^{1}$
}

\section{Introdução}

Neste trabalho apresento uma narrativa sobre os percalços pelos quais passei durante a etnografia multi-situada (Marcus, 1995) do processo migratório nipônico para o doutorado e as demais etapas desta etnografia, iniciada ainda na graduação (2000). Vou apresentar a etnografia multisituada sobre a construção da rede transnacional Uchinaanchu ${ }^{2}$ realizada no Brasil (Distrito Federal, São Paulo, Goiás e Paraná) Estados Unidos (O’ahu, Hawaii) e Japão (Okinawa, Miyakojima, Iejima, Naha, Nago, Yomitan, Shuri, etc.), acompanhando grandes eventos como as comemorações dos centenários da imigração japonesa e Okinawana no Brasil realizadas em São Paulo (separadamente em junho e agosto de 2008 respectivamente) o V Sekai no Uchinaanchu Taikai ou grande encontro de Uchinaanchu, realizado em Naha, capital de Okinawa em outubro de 2011. Paralelamente à etnografia de campo, acompanho pela internet muitas das atividades das associações e seus membros diretamente envolvidos neste esforço de construção desta rede transnacional.

Exponho aqui a trajetória de minha pesquisa desde sua fase inicial, desenvolvida em Londrina, Paraná. Também situarei a trajetória da família Ojido, a família uchinaanchu responsável por despertar meu interesse em relação à comunidade uchinanchu. Descendentes de migrantes provenientes de Okinawa, que compartilhavam laços de pertencimento à comunidade uchinaanchu de Londrina, migraram como dekassegui para o Japão coabitando em uma família extensa. A flexibilidade em termos de ajuda mútua familiar na empreitada migratória, a coesão familiar, a valorização dos estudos e da cultura uchinaanchu ficou fortemente impressa desde este contato. Em um primeiro momento me dediquei a pesquisar em Londrina - PR o movimento migratório Dekassegui ${ }^{3}$. Conheci então uma família Uchinaanchu que além de demonstrar uma

\footnotetext{
${ }^{1}$ Universidade de Brasília, Brasil.

${ }^{2}$ Uchinaanchu é a auto denominação dos descendentes do antigo reino de Uchinaa (nome utilizado internamente) ou Ryukyu (a forma como se referiam ao reino em conversas com estrangeiros).

${ }^{3}$ Dekasegui - termo japonês que significa literalmente trabalhar fora de casa, pejorativamente aplicado aos próprios japoneses provenientes de áreas menos favorecidas economicamente como Hokkaido, Sapporo, Aomori ao norte e Okinawa, Kumamoto, Kagoshima ao sul que se mudam sazonalmente para as áreas
} 
trajetória bastante particular na migração laboral, me revelou as especificidades culturais, históricas e identitárias de Okinawa, um conjunto de ilhas ao sul do Japão que viveu até 1879 de forma independente. (Nitahara Souza, 2004)

No mestrado ressaltei os contrastes identitários construídos entre "Japoneses" e "Uchinaanchu" realizando pesquisa de campo na Associação Okinawakenjinkai em Vargem Bonita - DF e nas comemorações do centenário da imigração Japonesa (junho de 2008) e Okinawana (agosto de 2008) em São Paulo. A existência de uma rede transnacional foi constatada ante ao intenso fluxo de informações e pessoas, bem como ao fato de compartilharem a identidade, práticas culturais, artísticas e o chamado Mabui, o espírito Uchinaanchu. (Nitahara Souza, 2009) Outro fato notável é o intenso fluxo de estudantes e professores nesta rede que envolve Estados Unidos (principalmente, mas não somente Hawaii) Brasil, Peru, Argentina e Bolívia, onde a comunidade Okinawana é expressiva. (Nitahara Souza, 2014)

Tal como Gramsci (1982) fala sobre os intelectuais orgânicos, os japoneses consideram os seus sensei (professor, em amplo sentido), por formar visões de mundo, não apenas em espaços acadêmicos, mas também em artes, artesanatos, línguas, músicas. Assim o foco geral da pesquisa de doutorado é desvelar a maneira como este grupo de intelectuais tem construído a rede transnacional Uchinaanchu. Etnografar a construção da rede transnacional Uchinaanchu focando a produção e fluxo de conhecimento sobre si mesmo, bem como mantendo o senso de pertencimento étnico a partir de práticas de intercâmbio de estudantes e sensei. Esta rede transnacional, ao fazer fluir elementos e conhecimentos caros à identidade, cultura e Espírito Uchinaanchu, nos fornece um exemplo de uma globalização não hegemônica (Ribeiro, 2014) de ordem não econômica, uma vez que não é movida por valores puramente capitalistas como os produtos chineses. Ao contrário, impulsionada por práticas tradicionais associativista informais e de ajuda mútua, bem como pela habilidade pessoal em formar redes, apreciada e incentivada culturalmente entre os Uchinaanchu.

Esta etnografia multisituada (George Marcus, 1995) teve lugar no Hawaii por dois meses (fevereiro e março de 2013), em Okinawa por sete meses (outubro de 2011, dezembro de 2013 a junho de 2014) e se iniciou no Brasil (Paraná, São Paulo, Goiás e

industrializadas centrais como Tokyo, Hamatsu, Saitama, Nagoya, Yokohama, aichi, Osaka. Com a ida e regulamentação legal da imigração trabalhista, elegendo a ampla colônia nikkey para morar e trabalhar em território japonês, o termo dekassegui designa os nikkey que realizam uma migração de retorno ao Japão, bem como a própria dinâmica migratória de retorno efetivada pela colônia nikkey desde a década de 80. Nikkey é o grupo formado pelos Emigrantes Japoneses seus descendentes fora do Japão. 
Distrito Federal). Em Brasília a Okinawakenjinkai ou Associação dos imigrantes da província de Okinawa se localiza em uma vila chamada Vargem Bonita. Brasília é uma nova (1960) e planejada cidade, durante a construção da nova capital, uma grandiosa obra (vista sob a perspectiva dos trabalhadores em Ribeiro, 2008), o governo brasileiro tentou implementar a produção agrícola para alimentar os trabalhadores da construção. Italianos e Alemães foram convidados e a eles foram cedidas terras. Porém eles abandonaram a terra devido a ser um solo pobre e ácido, que necessita de correção. Brasília está localizada em uma área de Cerrado, um bioma similar à Savana africana. (No Brasil existem cinco diferentes biomas, as florestas Amazônica e Atlântica, Caatinga, Pampas e Cerrado). Então o famoso presidente JK (Juscelino Kubitschek) convidou 10 famílias diretamente de Okinawa dizendo "somente os japoneses serão capazes de produzir aqui!” Acompanhei as atividades da Okinawakenjinkai de Brasília como Okinawa Festival, festa do Dia das mães, festa de Ano Novo (no calendário Chinês), festas tradicionais brasileiras como feijoada e festa junina, a Japonina, treino e apresentações de Taiko (filial do RKMD Ryukyu Koku Matsuri Daiko), aulas de Odori, Nihongo e karatê de 2007 a 2012.

Em outubro de 2011 acompanhei o V Sekai no Uchinaanchu Taikai, ou encontro mundial de Okinawanos. Em fevereiro e março de 2013 acompanhei e entrevistei membros da comunidade Uchinaanchu do Hawaii onde acompanhei o Fórum sobre as bases militares Americanas em Okinawa, assisti apresentações de Taiko, Participei da festa de ano novo da YOAH, Associação dos jovens Okinawanos no Hawaii, apresentações e ensaios de Odori, aulas, palestras e apresentações de Sanshin. Assisti a dois shows da famosa banda de Okinawa chamada Beggin, assisti aulas de Uchinaaguchi, de culinária com pratos típicos Okinawanos, acompanhei reuniões, palestras, aulas, congressos. Entre dezembro de 2013 e junho de 2014 realizei pesquisa etnográfica em Okinawa, onde pude participar de manifestações políticas, debates, shows, ensaios, aulas de Uchinaaguchi, palestras, reuniões, cerimônias oficiais de encerramento do período da bolsa com apresentação do que o bolsista aprendeu e sua despedida, além de realizar cerca de setenta entrevistas com participantes nos programas de bolsas, professores, músicos, jornalistas, ativistas, curadores de museu que se esforçam por construir as conexões que tecem a rede transnacional Uchinaanchu.

Pude perceber que além das características diferenciadas de ethos e identidade, os Uchinaanchu clamam por ser mais calorosos e receptivos do que os japoneses, 
considerados frios e formais. A sociabilidade, e também as trajetórias de ambos os grupos, Nihonjin e Uchinaanchu comprovam flagrante contraste. Por um lado temos os Nikkey, mesmo se eles nasceram no Japão e emigraram, os isei ${ }^{4}$ quando retornam ao Japão como Dekassegui, eles são discriminados pelos Japoneses. Mesmo seus nomes, originalmente escritos em kanji, são escritos em katakana ${ }^{5}$ ou mesmo são trocados. Ocorrem então múltiplas negociações identitárias, no sentido de que a experiência migratória Dekasegi faz com que quem participe se considere Japonês no Brasil e Brasileiro no Japão (Fukasawa, 2002). Entre os Uchinaanchu, por outro lado, eu percebi que os laços de socialidade formam um tecido conectando vários países.

Pude assim conduzir uma rica pesquisa de campo etnográfica que acredito me levará a escrita de uma interessante e instigante tese de doutorado sobre um intenso e vívido fluxo de pessoas, informações e amizades que atravessa oceanos e continentes por muitos países. Tal rede ou tecido de relações está sendo construído por meio de um intenso, planejado, orientado, intencional e direcionado esforço em conectar um fluido tecido de relacionamentos e amizades através do que eles chamam de Espírito Uchinaanchu.

\section{Trajetória da pesquisa etnográfica}

Exponho aqui o resultado de minha pesquisa inicial (Nitahara Souza 2004), desenvolvida em Londrina, Paraná. Também situarei a trajetória da família Ojido, a família uchinanchu responsável por despertar meu interesse em relação à comunidade uchinanchu. Descendentes de migrantes provenientes de Okinawa, que compartilhavam laços de pertencimento à comunidade uchinanchu de Londrina, migraram como dekassegui para o Japão coabitando em uma família extensa. A flexibilidade em termos de ajuda mútua familiar na empreitada migratória, a coesão familiar, a valorização dos estudos e da cultura uchinanchu ficou fortemente impressa desde este contato. No início da pesquisa busquei representações dos chamados Dekasegui brasileiros acerca de sua experiência e identidade ao circular entre países opostos pelo globo - Brasil e Japão. A

\footnotetext{
${ }^{4}$ Isei - Primeira geração, os japoneses que emigraram. Seus filhos nascidos fora do Japão são Nisei, netos sansei e bisnetos yonsei.

${ }^{5} \mathrm{Na}$ língua escrita japonesa se utilizam três alfabetos, os kanji incorporados da China, o hiragara composto por fonemas que complementam os kanji e o katakana, fonemas utilizados para escrever palavras estrangeiras.
} 
efetiva ida a campo foi atrasada por um acidente automobilístico ocorrido no dia anterior a que estava marcada a viagem. Devido a uma violenta colisão traseira fui atirada para fora do carro, que capotou. Por muita coincidência o motorista que causou o acidente, Leonardo Thompson Flores, por ter familiares com cargos nas altas instâncias, foi blindado pela justiça ${ }^{6}$. Assim ainda não completamente recuperada parti para Londrina a fim de etnografar as famílias envolvidas no movimento dekassegui. Para conseguir contatos com dekasseguis e seus familiares acompanhei minha avó a um evento comemorativo do dia das mães no clube nikkey de Londrina, chamado ASCEL, onde encontrei tal família. Mesmo sendo desconhecida completamente por aquela comunidade consegui obter neste evento muitos contatos de pessoas dispostas a conversar comigo sobre a experiência de ter trabalhado no Japão ou ter membros de sua família imersos nesta dinâmica migratória marcada por um recorte étnico e legalmente documentada. Assim obtive relatos sobre a vida no Japão, as mudanças de hábitos, os choques culturais e de pertencimento e marcadamente a negociação identitária inerentes a este fluxo de modo muito mais frequente do que relatos acerca de reconfigurações familiares como eu havia previsto. (Moriya, 2000; Lesser, 2003, Woortman 1995; Sasaki, 1999; Kawamura, 1999; Fukasawa, 2002; Galimbert, 2002) O contato extremamente caloroso e comensal que tive com a família Ojido revelou uma sensível distinção com a postura extremamente formal da maioria dos japoneses com que convivi em Londrina. Este contato despertou-me o interesse em investigar mais a fundo a especificidade cultural e identitária uchinanchu. Com aquela convivência percebi uma construção identitária contrastiva em relação aos nihonjin (japoneses) baseada fortemente no modo de ser, nos sentimentos, no ethos, no espírito uchinnchu. A família, em conversas bastante informais, declarou que não era japonesa. Muitos propalaram uma maior afinidade cultural e identitária entre eles e os brasileiros. Afirmaram que seu temperamento expansivo, comunicativo e caloroso tem origem em uma cultura bem mais aberta historicamente do que a do Japão. Muitos membros da família uchinaanchu citaram a valorização dos laços de família e do carinho entre seus membros como mais

\footnotetext{
${ }^{6}$ Leonardo Thompson Flores é neto de um antigo ministro do STF e filho de um dos sócios proprietários de um centro Universitário de Brasília. Assim a Juíza, concluiu a audiência de conciliação afirmando que “o Leo está prestes a se formar e um processo pode prejudicar a obtenção de sua carteira da OAB." Assim foi marcada uma segunda audiência, onde se decidiu pela retirada do processo mediante o pagamento, em cheque para 30 dias, de RS1. 500,00. O cheque foi devolvido e posteriormente resgatado. Isto ocorreu entre 2002 e 2003. Curiosamente em 2007 o nome de Leonardo esteve estampado em todos os jornais e revistas envolvido nos fraudes do exame da $\mathrm{OAB}$, pois teria recebido, durante a aplicação da prova, um telefonema de seu pai, também membro da comissão daquele exame.
} 
uma afinidade entre a cultura uchinaanchu e a cultura brasileira. Este elemento cultural, segundo a família Ojido, os distancia do jeito de ser dos Japoneses, considerados frios, rígidos, que colocam o trabalho e os amigos em precedência com relação à família. Citou-se inclusive o clima subtropical, propício ao cultivo de produtos agrícolas como banana, melão, abacaxi como um fator que os dotou de um temperamento mais caloroso. Okinawa é um arquipélago ao sul, possui belas praias, constituindo-se no balneário "tropical" do Japão. As características frequentemente ressaltadas relativas à hospitalidade, diplomacia, abertura são consideradas pelos uchinaanchu como fruto de um passado histórico de intensas, dinâmicas e fluentes relações políticas e comerciais. A postura política histórica do reino de Ryukyu, privilegiando as relações de cortesia e comércio, funcionando como um entreposto marítimo para negócios entre China, Ilha Formosa (Taiwan) e Filipinas, dotou os uchinanchu com a característica de serem mais abertos e extrovertidos que os japoneses.

A trajetória da família Ojido foi transversalmente trespassada pela dinâmica dekassegui. O modo como os membros desta família se engajaram nesta dinâmica, porém, me pareceu deveras diferenciado dos demais dekassegui com que convivi em Londrina. Quando estive com eles, muitos membros da família extensa se encontravam trabalhando e residindo no Japão. A maleabilidade desta família extensa se revelou nos arranjos estabelecidos para as co-residências durante a permanência de seus membros separados em polos opostos do globo terrestre. Gravei entrevistas primeiramente com uma família nuclear. Em um momento posterior, a mãe desta primeira família marcou uma conversa com dois irmãos seus em sua casa. Irmão e irmã, na época da pesquisa de campo, residiam juntos. Ficaram no Brasil cuidando dos filhos e sobrinhos para que estudassem no país. Seus cônjuges se encontravam no Japão, juntamente com outros membros da família extensa. Os membros desta família me revelaram que na época que residiram no Japão, alugaram uma casa grande para os padrões japoneses. Nesta casa chegaram a residir até 15 pessoas da família extensa. As crianças eram acompanhadas em seus estudos, sendo auxiliadas nas tarefas da escola no Japão ao mesmo tempo em que o conteúdo das escolas brasileiras era ensinado a elas por uma tia professora. Os momentos de lazer, relacionados principalmente à comensalidade, em eventos de fim de semana como churrasco e feijoada, eram passados em família.

A decisão dos membros desta família nuclear de se fixar no Brasil foi definida pela vontade do filho mais velho de cursar o nível superior. Ele estava cursando 
fisioterapia na época da pesquisa de campo em Londrina. A intenção da família era voltar a trabalhar mais um período no Japão após a formatura do filho. Este jovem, então com 22 anos, foi a única pessoa com quem convivi em Londrina que havia estudado em escola regular japonesa. Em nossa conversa tive acesso ao cotidiano escolar no Japão, por meio de revelações interessantes e por vezes inesperadas. Ele comentou que se cobra muito o resultado da aprendizagem, pois mesmo que não aprenda o aluno não terá uma segunda oportunidade para isso. Não há reprovação, as turmas são formadas de acordo com a idade dos alunos. Ele relatou-me um episódio onde o professor de matemática esbofeteou a turma inteira, em fila, devido a um mau resultado na prova. Revelou-me ainda o papel diferenciado da escola na sociedade japonesa comparativamente ao Brasil. No Japão, a formação moral fica a cargo da escola. Se uma criança ou adolescente não se comportar como esperado, eventuais reclamações são dirigidas à escola, não aos pais. A manutenção da escola tanto em termos de limpeza das instalações quanto na distribuição de lanches e refeições fica a cargo dos alunos. As crianças permanecem na escola em período integral. Em nossas conversas, outro assunto que me fascinou foi sua verdadeira paixão pela cultura de seus antepassados. O interesse deste jovem em aprender a tocar Sanshin ${ }^{7}$ e a falar uchinaguchi foi revelado com um tom de preocupação em manter sua cultura e identidade viva.

\footnotetext{
${ }^{7}$ Sanshin - denominação de um instrumento com três cordas, cujo corpo é revestido de pele de cobra, central nas músicas típicas uchinanchu. É uma referência constante quando se fala de memória, das festas, cultura e da identidade uchinanchu.
} 


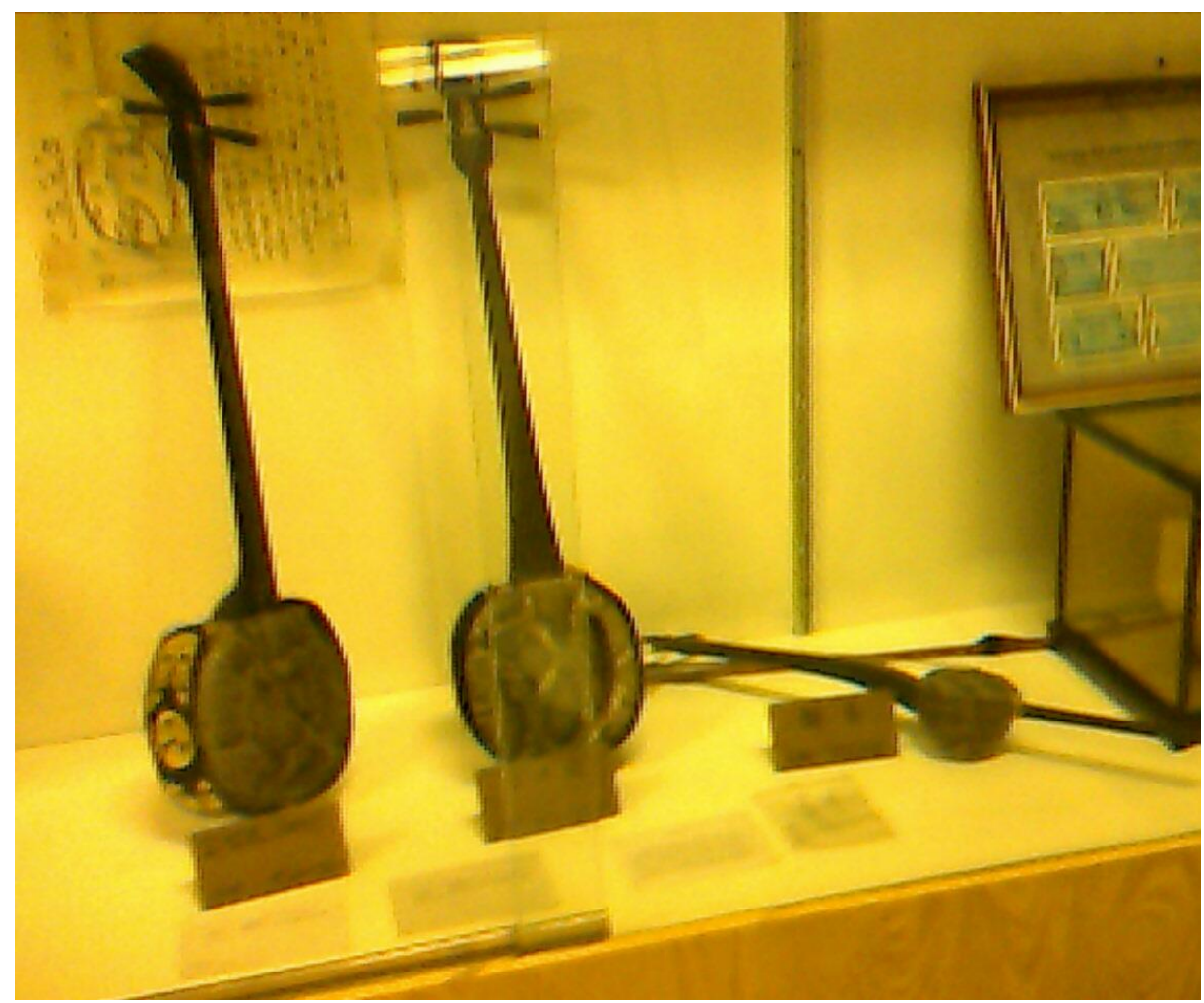

Sanshim no museu folclórico de Okinawa do Centro Cultural Okinawa do Brasil, em Diadema (SP).

A referência ao fato de os jovens da colônia nikkey estar cada vez mais cedo partindo como dekassegui se revelou enquanto uma preocupação crescente para os nikkey como um todo. Principalmente quando esta migração dekassegui representa o abandono do estudo e a falta de perspectiva de retornar ao Brasil e aqui estabelecer sua vida. Muitas trajetórias familiares dekassegui são marcadas pela inserção precoce dos jovens no árduo mercado de trabalho japonês. O ambiente de trabalho das fábricas revela um quadro identitário marcado por contrastes. Este quadro pode ser ampliado para envolver as relações da sociedade japonesa como um todo. Expressões como "os japoneses são como água e óleo, não se misturam" para se referir ao comportamento da maioria dos japoneses em relação aos "de fora", se aplica também entre os próprios japoneses. Segundo as falas dos Dekassegui brasileiros, as redes sociais do Japão constituem pequenos círculos de amizade e dificilmente incluem pessoas consideradas hierarquicamente inferiores. As diferenças marcantes são delineadas pela oposição entre "moderno" e "atrasado" que distingue as vilas montanhesas de rigoroso inverno ao norte bem como as ilhas subtropicais ao sul das cidades industriais do centro do Japão. Outra distinção fortemente operante no quadro identitário japonês e percebida 
claramente por quem vive no arquipélago vai além das diferenças regionais entre os próprios japoneses. Trata-se das diferenças étnicas entre os habitantes de Okinawa e os demais japoneses. A afirmação "Okinawajin não é japonês” tem também a sua recíproca por parte dos próprios uchinanchu, que afirmam, como vimos, não serem japoneses. A construção identitária contrastiva que envolve japoneses e Okinawanos se transferiu para a colônia nipo-brasileira. Em Londrina, há um clube da colônia japonesa chamado ACEL $^{8}$. Há também um clube correspondente formado exclusivamente pelos descendentes de Okinawa chamado ACROL (Associação Cultural Recreativa Okinawana de Londrina). Em Brasília a Associação Okinawa Kenjin utiliza o kaikan (espaço de socialização onde ocorrem eventos, esportes, aulas, reuniões), a sede da Associação Nipo-Brasileira de Vargem Bonita e seguem paralelamente. Apesar da maioria da população de Vargem Bonita ser de origem uchinaanchu as Associações não se fundem, ainda que organizem alguns eventos em cooperação. A justificativa para a existência de duas Associações separadas é feita no sentido de afirmar que os descendentes de japoneses não uchinaanchu não participariam de uma Associação Okinawa Kenjin, que possui muitos membros que não são de Vargem Bonita.

$\mathrm{Na}$ existência das associações nipônicas se imiscui o objetivo de se evitar casamentos interétnicos na colônia nikkey. Casamentos entre naichi e uchinaanchu, okinawajin e nihonjin ${ }^{9}$ não eram aceitos igualmente pelas famílias. Um nissei de Londrina casado com uma descendente de Okinawanos me revelou que sua família impôs forte resistência ao casamento dos dois. Ouvi de um uchinaanchu de Curitiba, ao ser questionado quanto à aceitação familiar do casamento de sua prima com um nissei naichi, que a sua tia preferia ver sua prima casada com um negro do que com um japonês. A expressão foi bastante espontânea, ele ficou se desculpando pela comparação politicamente incorreta, mas reafirmou que o sentimento era este mesmo. A prima justificou a atitude de sua família pelos sofrimentos infligidos aos uchinaanchu pelos japoneses na Segunda Guerra Mundial. Uma mulher de Londrina, ao me mostrar uma

\footnotetext{
8 “Oficialmente, a ACEL foi fundada em 1933, sob o nome de Associação Japonesa de Londrina (nihonjin-kai). Mas sua história se confunde com a própria história da colonização de Londrina. Em 23 de setembro de 1955, com a fusão da nihonjin-kai (Associação japonesa) com o seinen-kai (Associação de moços), também denominada Associação Cultural e Esportiva de Londrina, recebe a sigla ACEL, mantendo a denominação da associação dos moços: Associação Cultural e Esportiva de Londrina. Em 17 de janeiro de 1996 a ACEL passou a ter a seguinte denominação: "ACEL - Associação Cultural e Esportiva de Londrina - Centro Nipo-Brasileiro', cuja denominação permanece atualmente." http://www.acellondrina.com.br/

${ }^{9}$ Naichi $=$ Nihonjin $=$ japonês - o primeiro falado em uchinaaguchi, o Segundo a autodenominação.
} 
foto de sua filha com o marido frisou veementemente que o genro não era descendente de japoneses, que uchinaanchu é completamente diferente, um outro povo, outro país, que não se entende a língua que eles falam. De forma ampla, ao perguntar às pessoas sobre o relacionamento entre uchinaanchu e nihonjin obtive respostas parecidas quanto à diferença entre os grupos. Conforme depoimento do único dekassegui não-nikkey com quem convivi durante minha pesquisa em Londrina:

Eu trabalhei em fábrica onde tinha pessoas de Okinawa, e tinha o japonês de lá mesmo do Japão. Você acredita que eles discriminavam um ao outro? Aquele cara era Okinawajin e o outro era nihonjin, eles, entre um e outro, eles não se conversavam, eles não tinham afinidade, sabe. Ah não! Esse cara é de Okinawa. Ah, Okinawa é meio bagunçado, é meio diferente de nós. E o cara de Okinawa falava a mesma coisa. Eu não sou japonês, eu sou okinawano. Então eles, entre eles, têm essa divergência, sabe. (Sidnei Rodrigues, 21/05/03 Londrina).

De forma geral as falas dos nikkeys em relação aos Okinawanos se referem ao não pertencimento étnico ao Japão. Comentam-se sobre a cor da pele, mais morena, os cabelos crespos e a não compreensão da língua uchinaaguchi, diferente do nihongo. A questão racial é fortemente reportada. É de conhecimento geral, porém impreciso da comunidade nikkey o passado de independência política do arquipélago Ryukyu ${ }^{10}$. As primeiras notícias sobre o "reino da cortesia" aparecem em escritos chineses datados do ano 690. Como vimos, Uchinaa significa uma corda no mar em uchinaaguchi. Os uchinaanchu se consideravam homens do mar. Eram exímios navegadores e dominavam as rotas de ida e volta utilizando-se das correntes marítimas e assim praticavam o comércio com inúmeros povos do extremo oriente. O reino de Ryukyu manteve contato inclusive com o Japão Feudal apesar da não abertura oficial. A dominação de um reino estrangeiro conferia status a Kagoshima e seu Daimiyo clã de Satsuma (Kaneshiro, 2002) A queda da corte do rei Sho Tai em 27 de março de 1879, com sua retirada do palácio de Shuri para o exílio na China, é um episódio que marca o fim do reino de Uchinaa política e administrativamente independente, denominado Ryukyu Shobun. Kojima (2007) comenta sobre um termo cunhado para a o episódio histórico da anexação.

\footnotetext{
${ }^{10}$ Em 1872, sob a expansão imperialista da era Meiji o arquipélago é dominado pelo Japão. Após a segunda guerra Okinawa é mantida sob domínio norte americano, segundo um acordo entre os governos, até a reversão em 1972 (porém mantidas as bases militares norte americanas).
} 
Ryukyu Shobun is the term used to point to the historical event of the Ryukyu Kingdom being forcefully annexed into the Meiji Government of Japan as one of its prefectures. [...] an undeniable case of victimazation, starting from the year 1872; this was the point at which political actions were initiated by the Meiji Government to include Ryukyu as part of the new Imperia Japan.” (Kojima, 2007: 161)

Já nesta primeira etapa da pesquisa de campo etnográfica pude ver minhas suposições levantadas previamente para o projeto de pesquisa não serem confirmadas pela pesquisa de campo. A intenção seria pesquisar a questão familiar e matrimonial, e de fato me deparei com situações e depoimentos espantosamente francos e abertos acerca de questões íntimas e delicadas como términos de relacionamentos, novos relacionamentos, violência, apropriação indébitas de altos valores e bens, traições. Houve entrevistas onde a presente situação levou uma mulher a me relatar fatos que poderia ser entendido com um desabafo íntimo e urgente. Seu marido havia estado vivendo no Japão por mais de uma década, as circunstâncias de sua ida foi em meio à revelação de que seu marido havia tido um filho da mesma idade de sua filha caçula. Naquele momento ele havia retornado à casa, no entanto ela já estava envolvida afetivamente com outra pessoa. Uma outra mulher me recebeu e relatou me que quando viajou ao Japão sua situação de dependência financeira com relação ao marido a colocava em situações de humilhação. Assim sua decisão de ir ao Japão foi considerada por ela como uma válvula de escape. Todo o dinheiro que ela depositou em mais de uma década de trabalho foi furtado por seu marido, que segundo suas desconfianças, já mantinha um relacionamento com outra mulher, mãe de quatro filhos, sua atual companheira, enquanto ela trabalhava no Japão. Tal relacionamento foi descoberto quando esta mulher esteve no Brasil, e sem ter ao menos o dinheiro da passagem, rompeu relações se divorciando, retornou ao Japão e voltou ao trabalho. A entrevistei quando ela retornava pela segunda vez ao Brasil, agora com independência financeira e solteira. Sua única filha, após passar por uma experiência de assalto a banco em Londrina, decidiu não retornar ao Brasil.

No entanto o que mais marcou a pesquisa em campo foi o fator migração não ter sido reportado em nenhum momento, ou mesmo relacionado como a causa de tantas situações de ruptura. Foi sempre tido como uma válvula de escape ou uma maneira de protelar uma situação por si já insustentável. Ao contrário, obtive maior número de relatos onde a migração do casal fortaleceu e amadureceu o relacionamento. Ou mesmo quando relatos de permanência do casamento em meio a distância global contribuiu 
para um maior conforto material e investimento em educação dos filhos. Nestes casos as famílias vivenciam o cotidiano marcadamente determinado pela carga de trabalho do sistema japonês, incorporando muitas vezes filhos ainda jovens. A socialização destes dekasegui e suas famílias se restringe a um pequeno grupo, de brasileiros ou outros estrangeiros no ambiente de trabalho nas fábricas ou bentoya ${ }^{11}$, e também nos alojamentos, revelando uma segregação a ponto de haver um incidente onde um político defendeu publicamente a separação dos espaços de residência por etnia.

Nesta etapa da pesquisa, ainda na graduação, conheci, como disse, uma família Okinawana em Londrina - PR, cuja experiência migratória se mostrou diferenciada das demais famílias. Por estar em um grupo numeroso, esta família convivia e realizava encontros, churrascos e reuniões entre família e assim não sentiu falta da socialização no Brasil. A migração da família extensa possibilitou, por exemplo, que os filhos desta família Okinawana prosseguisse os estudos, tendo sido o único jovem com quem conversei que frequentou o sistema de ensino Japonês. Paralela e adicionalmente manteve o conteúdo dos estudos no Brasil, ensinados, junto com todas as crianças da família, por uma tia professora. Isto possibilitou que este jovem fosse aprovado no vestibular, e sua família nuclear se estabelecesse no Brasil. Mesmo assim esta família extensa organizou-se de modo a que parte permanecesse no Japão trabalhando e parte no Brasil dando prosseguimento aos estudo dos jovens da família extensa. De modo caloroso e receptivo esta família ampliou minha rede de contatos agendando outras entrevistas com outros membros e ressaltou o contraste identitário em relação aos demais japoneses.

Internamente chamado de Uchinaa ou uma corda no mar, o arquipélago possui privilegiada e estratégica posição geográfica, sendo considerado a porta do pacífico. Seus habitantes se consideram homens do mar, ou minchu, por serem exímios navegadores e assim atingirem grandes distancias utilizando as correntes marítimas e monções. Trata-se de um grupo cultural e etnicamente distinto, cujo passado histórico de independência política e intensas relações diplomáticas e comerciais com China,

\footnotetext{
${ }^{11}$ Indústria de preparação de alimentos prontos para serem consumidas, embaladas em bandejas, denominado bento. Pelas inúmeras lojas de conveniência 24 horas denominadas Conbeni, estações, mercados e lojas as bandejas de bentô são amplamente distribuídas diariamente. As bentoya empregam muitas mulheres dekasegui, que por funcionarem mesmo nos dias de feriado, muitas vezes 24 horas por dia, apresenta a possibilidade de muitas horas extra e a "vantagem" de não parar nos 10 dias de folga coletivas do sistema japonês (distribuídos entre ano novo, março, maio e agosto), pois recebem por hora trabalhada.
} 
Coréia, Filipinas, Tailândia, Taiwan e mesmo Japão fizeram com que o reino de Ryukyu fosse conhecido como a terra da cortesia. Wade (2007) detalha o amistoso e intenso relacionamento do reino de Ryukyu registrados nos anais da dinastia Ming, denominado Ming Shi-Lu e outros registros dos vínculos diplomáticos co outros reinos. É bastante notável nestes registros o empenho em realizar intercâmbios intelectuais em artes de governo, técnicas de construção de navios e artesanatos. Outra prova de suas relações amistosas com a China é a fundação de Kume Jima, um bairro próximo ao porto de Naha, doado com isenção de impostos para receber imigrantes chineses mestres em engenharias navais, artesanatos, artes de governo e inúmeras outras habilidades, como um sinal de cortesia por parte da Dinastia Ming.

\begin{abstract}
Segundo fontes chinesas, a fundação da comunidade de imigrantes representava um gesto de generosidade em prol do bem estar dos Ryûkyûanos - uma concessão da graça imperial chinesa, o soberano de Ming. Através desse bairro, os habitantes da ilha aprenderiam melhores métodos de construção de navios e assimilariam a arte mais adiantada da administração pública chinesa. Os okinawanos receberam os imigrantes com expressões de gratidão. Aos recém-chegados foram doadas terras isentas de impostos, perto do ancoradouro de Naha, obtiveram privilégios sociais especiais na corte de Shuri, gozando de grande prestígio. A função dos moradores de Kume Mura consistia em grande parte em elaborar documentos diplomáticos, que ganharam volume com a intensificação do comércio, participar das missões à China, servir de intérprete, ensinar a arte da navegação e da escrita chinesa, kanji - uma respeitável gama de atividades técnicas e intelectuais. (Yamashiro, 1993, 80-81)
\end{abstract}

O processo de diáspora se iniciou por iniciativa do pai da Emigração Okinawana Kyuzo Toyama em 1899, inicialmente para o Hawaii, vinte anos após a anexação ao Japão sob o nome de Okinawa ken (província). No navio Kasato Maru que aportou em Santos em junho de 1908 cerca de 42\% eram Okinawanos, cuja língua os demais japoneses não compreendiam. A este tempo os Uchinaanchu falavam uma língua distinta, chamada Uchinaaguchi, que não é mutuamente compreensível. O sistema educacional japonês aboliu a língua em Okinawa, tendo utilizado castigos e humilhações para tal fim. Hoje é mais usual ouvir a língua fora de Okinawa, em lugares para onde emigraram, como Bolívia, Peru, Argentina, Brasil, Hawaii, Estado Unidos. A comunidade Uchinaanchu se estabeleceu em locais e demonstrando uma dinâmica diferente da dos demais japonese migrantes. Cidades como Campo Grande receberam, devido à existência das redes de shimanchu (conterrâneos), Okinawanos vindos não somente de Santos e São Paulo, mas também do Peru e Argentina. Posteriormente com a formação da colônia Okinawan na Bolívia o fluxo de pessoas e informações entre estes países além de Okinawa tem se mantido intenso. 
Tal construção identitária contrastiva (Barth 1969) entre os descendentes de Japonese e os Okinawanos no Brasil foi foco da pesquisa de mestrado, que ocorreu em meio às comemorações do Centenário da Imigração Japonesa no Brasil em 2008. As distinções culturais trazidas de terras nipônicas se ressaltaram no Brasil, fazendo com que as comunidades se estabelecessem em cidades separadamente, como Campo Grande ou mesmo em bairros específicos da Cidade de São Paulo, que abriga a maior população nikkey do país. Acompanhei as duas comemorações realizadas em São Paulo, em junho de 2008, no sambódromo do Anhembi. As apresentações japonesas como kendo, judô, Odori, taiko, radio taisso, foram permeadas com algumas atrações Okinawanas como Odori com a bingata e o taiko okinawano, uma versão modernizada do Eisa, onde os tambores são tocados amarrados ao corpo ou seguros pela mão em meio a coreografias enérgicas e vigorosas, enquanto o taiko Japonês é apoiado e fixo. Em agosto retornei a São Paulo para acompanhar as comemorações do centenário da imigração okinawana no Brasil, realizado no kaikan da vila Carrão e na sede da Associação Okinawakenjin do Brasil em Diadema, grande São Paulo. Após acompanhar dois dias de intensa programação, incluindo o desfile das delegações de Uchinaanchu vindos de diversos países para as comemorações do centenário, me deparei com o primeiro grande "percalço e desafio" da pesquisa de campo. Em um lapso de cerca de uma hora em que meu computador foi deixado no carro seu vidro foi quebrado e o computador furtado. Hoje em dia penso que foi muita sorte eu não ter ficado sem meu carro. Mas naquele momento este fato representou um prejuízo muito superior ao valor da máquina. Em um tempo onde ainda não existia, ou pelo menos eu não conhecia dropbox ou icloud e mesmo HD externo era um item caro, havia cerca de dois meses que eu não gravava os dados em CD. Não apenas por não iniciativa, mas neste ponto devo admitir que minha capacidade em lidar com tecnologias é bastante restrita, a ponto de ser considerada pela minha irmã mais nova como eu sendo da geração $X$ e ela da geração Y. Naquele computador estava o começo da dissertação de mestrado, muitas entrevistas transncritas e um inestimável número de fotos e vídeos feitos durante importantes momentos da pesquisa de campo, a própria comemoração onde eu me encontrava, a comemoração do centenário da imigração japonesa acontecida pouco tempo antes, a visita oficial do príncipe Nahurito no palácio do Planalto e na Câmara do deputados. Assim tenho um profundo pesar por ter perdido registros dos momentos após os discursos oficiais, onde o príncipe quebrou todos os protocolos. Estava sendo 
noticiado que durante os cerimoniais e a por toda a visita do príncipe não se deveria tocar nele, nem ao menos um aperto de mão, não se deveria olhar em seus olhos ou mesmo rosto, somente se cruzaria seu caminho por suas costas e uma série de outros protocolos. No entanto fotografei o príncipe apertando a mão de três rapazes vestidos como gueixa, entre inúmeras outras pessoas, circulando e cumprimentando as pessoas nos saguões da câmara. Ao ser apresentado à miss nikkey não se conteve e a abraçou, segurou em sua mão para posar para fotos. Os registros em fotos e vídeos realizados na grandiosíssima festa no Anhembi, a movimentadíssima festa da Vila Carrão e em Diadema foram todos perdidos. Estes fatos e outros percalços revelam o modo como os acontecimentos da vida pessoal interferem na pesquisa etnográfica, uma vez que estão imbricados e afetam profundamente a própria pesquisadora.

O início do curso de mestrado em 2007 coincidiu com os preparativos e com o burburinho em torno das comemorações do centenário da imigração nipônica para o Brasil. Completava-se, em 2008, um século do estabelecimento da colônia nikkey no Brasil, uma data histórica que mereceu atenções da mídia e dos governos brasileiro e japonês. Ao longo do ano de 2007, foram amplamente divulgados os planos e eventos programados para a comemoração, como por exemplo, o lançamento de uma moeda comemorativa - estampando a colônia nipo-brasileira trabalhando nas lavouras de café pelo governo japonês. O lançamento oficial da moeda comemorativa foi marcado para a data do centenário da partida do navio Kasato Maru que, em 28 de abril de 1908, saiu do porto de Kobe rumo ao Brasil. Já no fim do segundo semestre de 2007 se iniciou uma intensa sequência de eventos comemorativos diretamente relacionados ao centenário da imigração japonesa no Brasil. O tema "centenário" apareceu associado aos mais diversos tipos de evento. As associações nipônicas, o governo japonês mediante a embaixada e consulados, o governo brasileiro nas mais variadas instâncias e instituições, empresas públicas como Correios e Infraero e mesmo associações como a ABIC (Associação Brasileira da Indústria de Café) participaram ativamente de inúmeros eventos como shows, exposições, festas, apresentações culturais, lançamentos editoriais. O lançamento de um selo comemorativo pela Empresa Brasileira de Correios e Telégrafos, no dia 18 de junho de 2008, foi um ato oficial dentre muitos. A visita do príncipe Naruhito, em uma apertada agenda que incluiu a visita às cidades nas quais a presença nikkey é proeminente, marcou com muita emoção os eventos comemorativos do centenário da imigração japonesa no Brasil. 
Em campo pude perceber a negociação identitária vivida por aqueles que se engajaram como dekassegui trabalhando por longos anos nas fábricas japonesas. Particularmente despertou-me muito interesse etnográfico o contato que mantive com uma família uchinanchu de Londrina que havia migrado como dekassegui. Além de a trajetória dekassegui desta família ter se mostrado bastante peculiar em relação às demais, a afirmação veemente e apaixonada de portarem uma identidade, cultura, sociabilidade, comensalidade, língua e ethos próprio e não japonês foi motivadora de um forte interesse de pesquisa.

A comunidade uchinanchu é um tema pesquisado por uma rede sediada na Universidade do Hawai, mas com pesquisadores também na Califórnia e em Okinawa. Com formações variando entre Sociologia, Antropologia, Ciência Política, Línguas e Artes este grupo lançou em 2007 o volume 42 da revista Social Process in Hawai'i voltado exclusivamente para a temática uchinanchu com o título "Uchinanchu diaspora - Memories, Continuities, and Constructions". Em um artigo, Yamazato (2007) analisa características adquiridas em experiências de vida marcadas por uma migração de retorno como um fator a distinguir uma minoria em uma colônia imigrante. Trata-se de os nissei kibei, grupo caracterizado por ter nascido nos Estados Unidos (sua pesquisa foi no Hawai) e ter sido enviado para ser educado no Japão. Dentre os nissei Kibei do Hawai o autor selecionou os uchinanchu, uma minoria dentro deste grupo marcado pela migração de retorno. Yamazato analisa histórias de vida de idosos que passaram parte substancial da infância e juventude sendo educados por parentes tanto no Japão como em Okinawa, anteriormente à Segunda Guerra. Sua análise é centrada na importância desse grupo de pessoas no sentido de formar as Associações Okinawa Kenjin como pólos articuladores de um processo de difusão do conhecimento cultural e espírito uchinanchu. Assim o autor considera as pessoas que viveram na terra de seus ancestrais uma minoria internamente ao grupo uchinanchu, por sua vez minoritário em relação à colônia nikkey do Hawai. Os Kibei Nissei Okinawanos são considerados como uma minoria dentro de uma minoria - os uchinanchu - por sua vez uma minoria internamente à colônia nikkey no Hawai.

De maneira semelhante vislumbrei que os dekassegui portam uma identidade diferenciada internamente a colônia nikkey brasileira. Ao pesquisar este grupo marcado pela experiência migratória internacional tive, como disse, um contato próximo com uma família uchinanchu de Londrina que se engajou no movimento dekassegui. Esta 
família tinha uma história bastante peculiar se comparada aos demais dekassegui. Este contato com o caloroso, solícito e comunicativo ethos uchinanchu sensibilizou-me para o fato de as diferenças culturais influenciarem diretamente a trajetória transmigrante. $\mathrm{O}$ ethos de cada cultura, japonesa e uchinanchu, determinou uma drástica diferença na estrutura atual da comunidade uchinanchu transnacional com relação à colônia nikkey. Transnacionalidade aqui entendida como uma condição, conforme ressalta Ribeiro (1997).

\begin{abstract}
... sua própria particularidade reside no fato da transnacionalidade apontar para uma questão central: a relação entre territórios e os diferentes arranjos socioculturais e políticos que orientam as maneiras como as pessoas representam pertencimento a unidades socioculturais, políticas e econômicas. Isto é o que denomino modos de representar pertencimento a unidades socioculturais e político-econômicas. Estes modos são centrais para a definição de alianças em múltiplos contextos de cooperação e conflito. São precisamente as formas através das quais nos integramos nestes guarda-chuvas simbólicos que estão mudando rapidamente com a globalização. O transnacionalismo coloca em perigo a lógica e eficácia de modos pré-existentes de representar pertencimento sociocultural e político. (Ribeiro, 1997: 2-3)
\end{abstract}

A acentuada divergência no pensar e negociar o pertencimento encontrado entre uchinaanchu e naichi resultou na formação de uma comunidade diaspórica transnacional uchinaanchu em contraponto com uma segmentada e compartimentada (a idéia é de organização da sociedade em numerosas caixas) colônia nikkey. Ambas encontram membros em múltiplo locais dispersos pelo globo, no entanto a certeza do pertencimento e reconhecimento da identidade uchinanchu contrasta com a intensa categorização operante entre japoneses, nikkey, nipo-brasileiros, ainoko (mestiços), dekassegui. A representação do pertencimento por ambos os grupos se mostrou, em campo, enquanto um pilar a distinguir radicalmente as trajetórias uchinaanchu e nikkey inseridas na era da globalização. O tão falado espírito uchinaanchu simboliza, segundo eles próprios, uma unidade à qual seus membros se identificam e tem seu pertencimento reconhecido.

Com o interesse voltado à comunidade uchinaanchu dei início à minha pesquisa de campo em Vargem Bonita, Distrito Federal, com a Associação Okinawakenjin de Brasília, em novembro de 2007. Meu objetivo era analisar a trajetória da dinâmica dekassegui como um contraponto fundamental em relação à trajetória da diáspora uchinanchu em suas diferenças marcadas pelos ethos das culturas uchinanchu e japonesa. Assim, um mosaico de identidade e jogos de pertencimento foi analisado em meio as diferentes estruturas transnacionais nikkey e uchinanchu, cuja construção 
ocorre em meio a trânsitos identitários envolvendo questões de raça e mestiçagem, afirmação étnica e linguística. As diferenças identitárias atravessaram o oceano. Em um contato com a colônia nipo-brasileira temos acesso a variadas maneiras de se perceber no mundo influenciadas pela experiência dekassegui. Os descendentes dos migrantes que hoje formam a maior população de nikkey fora do Japão possuem identidades algo peculiar neste cenário de fluxos transmigrantes. Ao ter contato com as redes sociais transmigrantes no âmbito de minha pesquisa de campo, pude perceber o modo como estas pessoas negociam suas identidades. A experiência transmigrante dekassegui faz com que as pessoas nela envolvida percebam e acionem contextualmente distintos pertencimentos a identidades culturais híbridas marcadas pelos fluxos migratórios circulares ao redor do globo. A colônia nikkey do Brasil mantém fortes laços de identidade cultural com o país de seus antepassados, o Japão. No Japão, o transmigrante se conscientiza de seu pertencimento identitário ao Brasil.

Uma dinâmica bastante diversa, praticamente oposta, é revelada ao etnografar a comunidade uchinaanchu. O maior contingente populacional de uchinaanchu fora de Okinawa se concentra no Brasil. Esta relação se aplica também à colônia nikkey brasileira, a maior fora do Japão. Enquanto a trajetória da colônia nikkey e principalmente os valores culturais e ethos ativados na relação nikkey/Japão estruturou uma polarização radical de pertencimentos étnicos, raciais, nacionais e identitários, ocorreu uma outra dinâmica na estruturação da comunidade global uchinaanchu. O estabelecimento dos grupos uchinaanchu em terras brasileiras ocupou locais distintos e distantes dos locais ocupados pela colônia nikkey. A imigração nipônica inicialmente se deu em São Paulo, onde permaneceram muitos nikkey e uchinaanchu. A migração secundária dispersou os imigrantes nikkey para o Paraná. Os imigrantes uchinanchu migraram secundariamente principalmente para o Mato Grosso do Sul e Pará. Mesmo em São Paulo o estabelecimento de nikkey e uchinaanchu se deu separadamente. Na grande São Paulo é sabido que japoneses de bairros como Vila Carrão e Casa Verde na verdade não são japoneses, mas Uchinaanchu. Campo Grande acolheu a maior colônia uchinanchu. Curiosamente o Soba se tornou um prato bastante apreciado na cidade. A facilidade em formar ligações estreitas, sociabilidade, flexibilidade descontração são características encontradas mais frequentemente entre os uchinaanchu do que entre os nikkey. A própria concentração de uchinanchu em Campo Grande e o exemplo dos que vieram do Peru para se fixar na cidade é obra da sociabilidade específica articulada em 
torno das práticas de ajuda mútua, cooperação e do sentimento de pertencimento à identidade e compartilhamento do espírito uchinaanchu.

As distinções têm sido afirmadas culturalmente, como são um forte exemplo a luta pela recuperação do uchinaaguchi e o contemporâneo "boom cultural Okinawano" na mídia japonesa, onde novelas cujo foco temático é Okinawa e cantores okinawanos estão fazendo um grande sucesso. A estreita ligação entre as associações Okinawa Kenjinkai é uma realidade. Um exemplo disto é a difusão do conhecimento acerca de danças típicas como o Odori de Okinawa e o Taiko de Okinawa. Há atualmente um intenso fluxo de pessoas e objetos entre as Associações Okinawakenjin regionais que se unem para formar a Associação Okinawakenjin do Brasil. Os Grupos de Odori e Taiko realizam apresentações onde participam representantes de Associações Okinawa Kenjin de vários locais. Chika (2007), com o intuito de dar voz às mulheres para falar sobre a experiência diaspórica uchinaanchu e casamentos interétnicos, fala sobre sua experiência em dançar Odori de Okinawa em uma Associação Okinawa Kenjin do Havaí. A autora discorre sobre o fundamental papel socializador que o grupo de dança exerce na manutenção e valorização da cultura como no estreitamento dos laços da própria comunidade uchinanchu no Havaí.

No mestrado etnografei a comunidade Nikkey (descendentes e japoneses fora do Japão) do Brasil focando os contrastes identitários existentes entre "Nihonjin" e "Uchinaanchu". Percebi que para além das características de ethos diferenciados com afirmações de serem mais calorosos, maleáveis e receptivos do que os frios, rígidos e perfeccionistas japoneses, a socialidade e também as trajetórias dos grupos Nihonjin e Uchinanchu se mostraram flagrantemente contrastantes. Enquanto os Nikkey, mesmo que tenham nascido no Japão, são discriminados pelos japoneses, fazendo com que ocorra uma negociação identitária no sentido de serem japonese no Brasil e Brasileiros no Japão, entre os Uchinaanchu pude perceber que os laços de socialidade formam um tecido vinculando diversos países. Assim cheguei ao ponto central do meu projeto de pesquisa para o doutorado, intitulado "Construindo a rede transnacional Okinawana: Intelectuais diante do espírito Uchinaanchu", cuja proposta é etnografar a construção da rede transnacional Uchinaanchu com foco na produção e fluxo de conhecimento sobre si mesmos, bem como na manutenção do sentimento de pertencimento étnico a partir de práticas de intercâmbio de estudantes e sensei (professor). A partir da constatação da existência de uma fluída e dinâmica rede transnacional Uchinaanchu a distinguir esta 
comunidade dos demais nikkei (japoneses e seus descendentes fora do Japão), apresento a questão central a ser analisada na tese: a forma como ocorre a construção e reprodução desta rede transnacional. Trata-se de uma comunidade diaspórica que está construindo uma identidade étnica transnacional em torno do espírito Uchinanchu por meio de intensos fluxos e articulações, dentre os quais destaco os intercâmbios. Percebi que as estruturas em torno das quais se articula e se mobiliza esta rede, como a WUB (Worldwide Uchinanchu Business), o Sekai no Uchinanchu Taikai (Encontro Mundial de Uchinanchu, cuja quinta edição, em outubro de 2011 etnografei), que tem também sua versão jovem (Wakamono Uchinanchu Taikai - Reunião Mundial de Jovens Okinawanos, Niseta tour e WYUA - World Youth Uchinanchu Association) e os grupos de apresentações culturais de Odori (dança) e Taiko (tambores) foram conscientemente planejadas e executadas por um grupo ou rede de intelectuais Uchinanchu. Com apoio do governo da província, a rede de intelectuais da diáspora Uchinanchu organiza em Okinawa, desde 1990, um grande encontro chamado Uchinanchu Taikai. Trata-se de um festival que ocorre a cada cinco anos e reúnem migrantes e descendentes de diversas partes do mundo, além dos moradores de Okinawa, com o objetivo de propiciar o intercâmbio e a experiência de compartilhar o espírito Uchinanchu. A vasta programação do evento inclui um desfile de recepção das delegações representantes de diversos países, devidamente uniformizados e com os símbolos, as músicas e danças dos seus países de proveniência (samba, passista, hula, colares, tango, mariachi, canguru, coala, chapéus e roupas tradicionais). Durante os dias do V Uchinanchu Taikai (12 a 16 de outubro de 2011) houve festival de grupos de eisa (dança folclórica) e taiko em um complexo esportivo e também muitas apresentações de odori (dança clássica) no castelo de Shuri, além de apresentação de espetáculos musicais e teatrais. Cada unidade administrativa de Okinawa - classificadas em Cho (cidades) Shi ou machi (povoados) Son ou mura (vilas) - organizou eventos paralelos para receber seus descendentes diretos. Paralelamente também se reuniram os grupos de negócio (WUB), de estudiosos da língua uchinaguchi e representantes das Associações okinawanas - Okinawakenjinkai - jovens e senhores presidentes. Segundo dados de um survey realizado por Noiri (2009) na edição do festival em 2006, dos 4.932 participantes do festival vindos de 21 países, cerca de $20 \%$ eram provenientes da América Latina. A edição de 2011 contou com cerca de dez mil pessoas. 
Entre os Uchinaanchu os laços sociais, as redes ou tecidos de relações tem mostrado uma fluída, intensamente vivida e conectando diversos países ao redor do globo com estruturas planejadas para articular a comunidade Uchinaanchu em diversas áreas. Analiso etnograficamente este evento e seu papel na construção da rede transnacional Uchinaanchu após minha participação no V Sekai no Uchinaanchu Taikai, um grande evento étnico que ocorre a cada cinco anos, foi pensado para congregar em uma grande celebração a identidade Uchinaanchu. Em eventos como o Sekai no Uchinaanchu Taikai e principalmente nas representações e discussões que gera, o evento em si provêm uma considerável fonte de recursos etnográficos para analisar a rede transnacional Uchinaanchu sendo construída.

Assim após ter passado pela banca de qualificação do projeto de pesquisa do doutorado parti rumo ao Hawaii. Anteriormente havia submetido um resumo para apresentar um artigo sobre a rede intelectual Uchinaanchu em uma conferencia anual de estudantes de pós-graduação do East West Center. Tal instituição, inserida na Universidade do Hawaii em Manoa, Honolulu, recebe estudantes de diversas etnias e origens, assim convivi com Indianos, Paquistaneses, Iranianos, Curdos, Iraquianos, Samoanos, Tchecos, Indonésios, Filipinos, Chineses, Vietnamitas em seus dois prédios dormitórios, Hale Manoa onde ficava meu quarto (com banheiro coletivo) e Hale Kuahina, um prédio mais baixo. Assim que cheguei ao Student housing aconteceu algo que de fato me abalou profundamente. Soube por meio de um formal aviso fixado dentro dos elevadores que havia ocorrido uma morte, e que se disponibilizava acompanhamento a quem estivesse "felling distressed". Meu quarto ficava no décimo segundo andar, o mesmo de onde uma estudante chinesa havia se atirado, soube alguns dias depois ao perguntar a outro morador, nós dois consternados em frente às coroas de flores e foto da garota suicida, que ocupou todo o hall de entrada por longas semanas. $\mathrm{O}$ tema da morte também ocupou as conversas anteriores às reuniões que acompanhei para a organização do Okinawan Talk Stories, um Fórum acerca das bases militares americanas em Okinawa.

Já na primeira reunião com os estudantes do clube Akisamiyo (clube de estudantes Okinawanos no Hawaii) me surpreendi com as respostas quanto à sua identidade. Afirmaram-se japoneses. Mesmo anteriormente, me encontrei com uma estudante do mestrado okinawana que me disse ser a primeira vez que se tocava neste assunto das bases militares. Ela, ao ver minha expressão de espanto ante as negativas 
identitárias, identificação como japoneses e questionamentos como "reclamam que os americanos cometem crimes, mas e os okinawanos, não cometem crimes?" olhou me erguendo os dedos indicador e médio em V e disse "Yeah, we are colony!" inclinando a cabeça e sorrindo acanhada. Curiosamente enviei e-mail e contatei a maioria dos estudantes por facebook, e o único que me respondeu e me levou a aula de sanshin foi um alemão estudante de música.

Ainda no Hawaii busquei contatos e entrevistei a presidente Joyce Chinen e outros membros do Center for Okinawan Studies, professores de diversos departamentos como história, linguística, letras e tradução, sociologia, ethnic studies, american studies, filosofia. Fui ao Hawaii em busca do COS - Center for Okinawan Studies e o EWC - East West Center, ambos na Universidade do Hawaii em Manoa, Honolulu. Qual não foi minha grata surpresa ao conhecer o Ukwanshin Kabudan grupo de artes de Ryukyu / Okinawa, que se encaixa perfeitamente na proposta do meu projeto de pesquisa. O Ukwanshin Kabudan é um grupo independente e sem fins lucrativos dedicado a preservar e perpetuar, por meio da prática e do ensino, a verdadeira, tradicional e pura manifestação cultural do antigo reino de Ryukyu. Não somente praticando as performances da arte da dança e música, o grupo fundado em 1999 mantém aulas, palestras, oficinas e viagens de estudos relativos a vários aspectos da história, língua e cultura Okinawana.

Pude entrevistar, quando estava realizando a pesquisa de campo no Hawaii, dois principais responsáveis pelo grupo, Eric Wada e Norman Kaneshiro. Norman publicou o artigo Uchinanchu Identity in Hawai'i no livro The Japanese American Contemporary Experience in Hawai'i editado por Jonathan Okamura (2002), onde fala da importância da música e do intercâmbio para a identidade Uchinaanchu. Norman e Eric conduzem vários tipos de atividades culturais e educacionais. Tais atividades são todas direcionadas a aprofundar o conhecimento e o verdadeiro valor dos sentimentos com relação a Okinawa e o antigo reino de Ryukyu ou Uchinaa.

A construção da rede transnacional Uchinaanchu se dá através da produção e fluxo de conhecimento sobre si mesmos, bem como mantendo um senso de pertencimento étnico a partir das práticas de estudantes e sensei. Gramsci (1982) fala sobre o intelectual orgânico formando concepções de mundo. Algo similar temos o significado dado ao termo japonês sensei. É aplicado, mesmo entre os Uchinaanchu, em amplo sentido, para designar, adicionalmente aos acadêmicos, os professores de artes 
tradicionais, pinturas, artesanatos como cerâmica, têxteis, vidro, agricultura, pesca, esportes, lutas, músicas, danças, instrumentos musicais, mitos, caligrafia, língua: uma ampla gama de conhecimentos e práticas, institucionalizados ou não. Em torno da disseminação deste conjunto de referências à identidade Uchinaanchu se articula de modo transnacional uma rede ou um grupo de intelectuais, seguindo o amplo sentido de sensei. Eric Wada e Norman Kaneshiro são ambos verdadeiros sensei esforçando-se (ganbaro) para manter vivo as musicas, danças, cultura e práticas do antigo reino de ryukyu. O fluxo e circulação de conhecimento sobre a cultura Uchinaanchu e suas práticas indica o processo de formação de uma identidade compartilhada por uma rede transnacional Uchinaanchu. Mesmo na apresentação formal no sítio da internet do grupo Ukwanshin Kabudan claramente podemos ver o ímpeto em conectar o local ao global por meio da prática, ensino e aprendizagem de artes como modo de articular uma identidade cultural tecida em laços glocais.

\section{Considerações finais}

Em minha pesquisa de campo pude perceber que os grupos Uchinaanchu instrumentalizam cultura, tradição, história, política, linguagem como elementos para construir uma identidade compartilhada em uma comunidade imaginada transnacional cuja história se constituiu através de relações supralocais com China, Japão, Estados Unidos e uma diáspora global. A rede Uchinaanchu instrumentaliza uma gama diferenciada de elementos como história, cultura, linguagem, política, tradições, artes para construir a si mesmos em conexões glocais. A manutenção e reprodução da cultura, língua e identidade é, devido às circunstâncias históricas e políticas, mais fortalecida na rede transnacional do que em Okinawa propriamente. Assim surgiu o termo suupa (super) Uchinaanchu para designar pessoas como Eric e Norman e grupos como o Ukwanshin Kabudan. Além destas pessoas consideradas suupa Uchinaanchu, em Okinawa entrei em contato, convivi e entrevistei muitas pessoas e iniciativas que também poderiam ser considerados como tal, muitas vezes estrangeiros descendentes de Uchinaa vindos dos países onde a colônia é significativa. Suas trajetórias de vida são marcadas por intenso fluxo de informações e mesmo estadas em Okinawa como bolsistas e mesmo para realizar a visita aos ancestrais em seus túmulos e no Totome ou santuário doméstico. Um ponto em comum na narrativa dos nascidos em Okinawa em 
relação à descoberta de sua identidade é a saída de Okinawa e a descoberta de não ser japonês, muitas vezes no contato contrastivo com os próprios japonese. Acompanhar este fluxo de Uchinaanchu provenientes de tantos países para Okinawa se mostrou em campo mais complicado e burocrático do que a início imaginei, em termos práticos de mobilidade humana e burocracias para o visto. Assim percebi que a grande maioria dos bolsistas permanecem por menos de três meses, assim não há maiores dificuldades com obtenção de visto, podendo ser o de turismo. Há bolsas oferecidas pelas 47 Prefeituras do Japão, chamada Kenpiryugakusei, onde o estudante se vincula a uma universidade e permanece por um ano em Okinawa. Alguns bolsistas obtêm empregos como, por exemplo, professores assistentes ou de línguas, ou mesmo em empresas e prolongam sua permanência em Okinawa modificando seus vistos. De modo geral o fluxo de pessoas para o Japão é rigidamente documentado e acompanhado. E a burocracia não contempla a etnografia como uma justificativa para permanecer no país por mais de três meses. É necessário uma instituição que formalize um vínculo e se responsabilize pelo estrangeiro em sua permanência. Assim tentei algum modo de obter o visto por meses com a ajuda de um parente que possui uma empresa de recursos humanos no Japão. No entanto, como eu não iria trabalhar, nossas tentativas restaram infrutíferas. Assim as passagens que haviam sido marcadas com cinco meses de antecedência foram remarcadas, gerando um gasto adicional que dobrou o custo da passagem. Cheguei a pensar em dividir minha estadia em duas etapas de três meses, quando meu orientador Gustavo Lins Ribeiro me procurou preocupado com a pesquisa. Ao expor a dificuldade burocrática pela qual eu passava ele lembrou que já havia recebido uma estudante japonesa da universidade de Osaka para realizar pesquisa de campo no Brasil. Então em certo sentido, meu orientador estava em crédito de gentilezas acadêmicas e assim fui recebida como pesquisadora visitante no GLOCOL, Global Collaboration Center da Universidade de Osaka. Após algumas reuniões com meu orientador no Glocol Gyo Miyahara parti para Okinawa para etnografar os agentes e agencias que atuam na formação das conexões, redes e tecidos de relações que abrangem diversos países e continentes. Ao contrário do que aconteceu no Hawaii, tive mais facilidade em acompanhar os estudantes estrangeiros em Okinawa do que os professores, principalmente os mais formais, nas instituições acadêmicas. Credito em grande parte este fato ao elevado status dos professores no Japão e também ao costume de considerar informações como e-mail uma informação pessoal e sigilosa. Por exemplo, fui 
apresentada a uma professora da universidade de Meio, da área de espanhol. Ela havia realizado seu doutorado sobre múmias no Peru e conhecia outra pesquisadora que se dedicou à migração Okinawana no Peru. Após muita insistência durante a entrevista, ela contatou sua amiga e obteve sua permissão para me fornecer seu e-mail. Uma outra demonstração da distinção dos professores enquanto profissionais de elevado status acontecia quando eu dizia que sou professora de ensino médio, quando me cumprimentavam reverencialmente, arregalam os olhinhos e me olhavam como se fosse inclusive muito rica. Tal reação sempre me deixava constrangida e ao mesmo tempo profundamente decepcionada e envergonhada com relação à situação de despreparo profissional e descaso que vivenciamos no Brasil com relação ao setor educação. Quando eu tentava explicar que não era dada tanta importância e muito menos se valorizava o professor, dificilmente era compreendida.

Os Uchinanchu estão dispersos em países como Estados Unidos, Peru, Brasil, Argentina, China, Philipinas, Bolívia e Cuba. A comunidade Uchinaanchu se estrutura de forma algo semelhante ao que Sahlins visualizou paras as comunidades de Samoa, Tuvalu, Ilhas Cook e Tonga, ou seja, atualmente se encontram dispersas pelo globo. Estas comunidades expandiram seus horizontes de possibilidades culturais e de sociabilidade por meio de conexões entre suas muitas comunidades em diferentes países. A representação de pertencimento a uma comunidade Uchinaanchu se mostrou na pesquisa de campo como um pilar a formar a identidade cultural e intensa sociabilidade da comunidade Uchinaanchu.

O reconhecimento e supervalorização da origem da identidade e herança Uchinaanchu é o principal incentivo a estimular as estruturas transnacionais a operarem no sentido de estabelecer conexões entre grupos Uchinaanchu dispersos por vários países. A construção desta rede se mostra dedicada a preservar os valores caros à cultura Okinawana, seus modo de viver e estar no mundo, refletindo e agindo conscientemente para a continuação, transferência para as novas gerações e fortalecimento do Espírito Uchinaanchu. Como o conceito Maori de Hau (Mauss) o Espírito Uchinaanchu estabelece laços na comunidade, valorizando a terra, natureza, alma, astral, clima, união da ilha de Okinawa. É como a força que concede fluidez às dinâmicas dos laços, o movimento dos objetos, informações e pessoas. É a força que possibilita a construção de redes formando o tecido social que dinamicamente agrega e articula a comunidade Uchinaanchu. Nas tradições o líder espiritual, uma mulher denominada Yuta costumava 
desempenhar o ritual para restabelecer o Mabui, ou alma para alguém que perdeu seu próprio espírito devido a um grande medo ou trauma. A meu ver hoje a geração jovem se parece com alguém que perdeu sua alma quando é comparado com algum Uchinaanchu fora de Okinawa que se esforça na luta para resgatar a herança cultural e identidade. A forte dominação ideológica por parte de ambos, Japão e Estados Unidos foi bastante efetiva em eliminar o orgulho de ser Uchinaanchu. Ouvi relatos sobre homens que escondiam da própria esposa sua origem okinawana. Não é incomum ouvir dos jovens okinawanos que eles são idênticos aos japoneses, não há diferenças e se orgulham de terem se tornado japoneses falando nihongo. Não é incomum ouvir dos Uchinaanchu que se identificam primeiramente como Uchinaanchu mesmo tendo nascido em outros países, que eles dão o sangue para manter viva a identidade e ver reconhecido o verdadeiro valor das manifestações culturais, enquanto em Okinawa as pessoas não se importam com estas questões. Estas pessoas foram chamadas Uchinaanchu normal, em uma entrevista que conduzi com a curadora do museu de Haebaru Tsugiko Taira, filha de Keiko Taira, sobrevivente do naufrágio do navio Tsushima Maru. Ela considera a si mesma e as pessoas em Okinawa como Uchinaanchu normais, que precisam trabalhar no sistema japonês, estudar no sistema japonês que não os possibilita saber mais profundamente acerca de seu próprio passado histórico independente. O sistema educacional japonês funcionou para banir o Uchinaaguchi, bem como substituir o orgulho de ser Uchinaanchu pela vergonha acerca deste legado cultural. Em uma entrevista com Hiroyuki Kinjo, professor na Ryukyu University, ouvi que os Uchinaanchu de fora estão agora ensinando aos Okinawanos que vivem em Okinawa a verdadeira paixão e como ser orgulhoso por ser Uchinaanchu.

\section{Referências}

BARTH, F. Ethnic groups and boundaries. The social organization of culture difference. Oslo: Universitetsforlaget, 1969.

CHINEN, J. Uchinaanchu Diaspora: Memories, Continuities and Constructions. Social Process in Hawai'i, volume 42. Honolulu: University of Hawai'i Press, p. 312, 2007.

FUKASAWA, M. Um Mundo Paralelo: a vida da comunidade brasileira de Oizuni, Japão. Rio de Janeiro: Topbooks Editora. 2002.

GALIMBERTTI, P. O Caminho que o Dekassegui Sonhou: Cultura e subjetividade no movimento dekassegui. Londrina: Editora Universidade Estadual de Londrina, p. 234, 2002.

GRAMSCI, A. Os Intlectuais e a Organização da Cultura. Rio de Janeiro: Editora civilização Brasileira, 1982.

KANESHIRO, N. Uchinanchu Identity in Hawai'i. In The Japanese American Contemporary Experience in Hawai ' $i$, ed Jonathan Y. Okamura. Honolulu: University of Hawai'i Press, p. 75 - 
94, 2002.

KAWAMURA, L. Para Onde Vão os Brasileiros? Campinas, SP: Editora da Unicamp, p. 236, 1999.

KERR, G. H. Okinawa: the history of an Islands People. North Clarendon: Charles E. Tuttle Publishing, 2000.

KOJIMA, S. Remembering the Battle of Okinawa: The reversion Movement. In Uchinanchu Diaspora: Memories, Continuities and Constructions. Social Process in Hawai' 'i, volume 42, ed by Joyce N. Chinen. Honolulu: University of Hawai'i Press, p 137-168, 2007.

LESSER, J. Searching for home abroad: japanese brazilians and transnationalism. Durham and London: Duke University Press, p. 47-66, 2003.

MARCUS, G. Ethography in/of the World Sistem: The Emergence of Multi-sited Ethnography. In Annual Anthropology review 24: 95-117. Palo alto: Annual Reviews. 1995.

MORIYA, R. Fenômeno Dekassegui: um olhar sobre os adolescentes que ficaram. Londrina: Editora CEFIL, p. 160, 2000.

NAVA, E. M e BONY, F. C. (org) La Otra Antropologia: Reflexiones sobre el oficio antropológico. Quito: Ediciones Abya Yala. 2014.

NITAHARA SOUZA, Y. A comunidade uchinanchu na era da globalização: contrastando "okinawanos" e "japoneses". Dissertação de mestrado, Departamento de Antropologia, Universidade de Brasília. Brasílias. 2009.

Dekassegui: Representação e Falas de Nipo Brasileiros em Londrina - PR. Monografia de Graduação, Departamento de Antropologia, Universidade de Brasília. Brasília. 2004.

Os Uchinanchu e sua rede intelectual. In NAVA, E.M e BONY, F. C. (org) La Otra Antropologia: Reflexiones sobre el oficio antropológico. Quito: Ediciones Abya Yala. 2014.

NOIRI, N. The Worldwide Uchinanchu Festival and Okinawan Network: features of participants from Central and South America. Immigration Studies, p. 27-40, 2009.

RIBEIRO, G. A Condição da Transnacionalidade. In Série Antropologia 223. Brasília. DAN UnB, p. 34, 1997

SASAKI, E. Movimento Dekassegui: a experiência migratória e identitária dos brasileiros descendentes de japoneses no Japão. In: REIS, R e Sales, T. (org.) Cenas do Brasil Migrante. São Paulo: Boitempo Editorial. 1999.

WADE, Geoff. Ryukyu in the Ming Reign Annals 138s-1580s. Asia Research Institute. Working Paper Series, $n$ : 93. National University of Singapore. July 2007.

WOORTMANN, E. 1995. Japoneses no Brasil, Brasileiros no Japão: Tradição e modernidade. Serie Antropologia 183, Brasília: DAN - UnB, p.20.

YAMASHIRO, J. Okinawa: uma ponte para o mundo. Cultura Editores Associados. São Paulo, 1993.

Recebido em: 16/03/2015

Aprovado em: 13/06/2015 